DOI: 10.2478/linpo-2014-0008

\title{
First and second language acquisition: Towards a reconcillation
}

\author{
Nicole Nau \\ Institute of Linguistics, Adam Mickiewicz University in Poznań, naunicol@amu.edu.pl
}

\begin{abstract}
Nicole Nau. First and second language acquisition: Towards a reconcillation. The Poznań Society for the Advancement of the Arts and Sciences. PL ISSN 0079-4740, ISBN 978-83-7654-384-0, pp. $125-140$

For the past two decades, research on first language acquisition on the one side, and on second language acquisition and learning on the other have largely developed separately, probably as a reaction to the failure of earlier attempts to use the same methods or simply transfer insights gained in one of the fields to the other. This article argues that a reconciliation may be fruitful, provided that different aspects which have often got blurred in the discussion are considered separately. These aspects include the assessment of multilingualism and monolingualism, the age factor and the definition of "first" and "second" language, the understanding of linguistic competence and of completeness of acquisition, different forms of acquisition and learning, and uniformity vs. individual differences in the process of language acquisition. By challenging some widely held views on characteristics of first language acquisition and its differences to second language learning, more fine-grained research questions are revealed, some of which have been addressed in recent studies on language acquisition and multilingualism.
\end{abstract}

Keywords: first language acquisition, second language acquisition, multilingualism

\section{Introduction}

The comparison of first and second language acquisition is a topic that has turned up repeatedly in various fields of linguistics, such as psycholinguistics, theoretical linguistics, or applied linguistics. The goals of such comparison, as well as its results, vary greatly. The question at the base of the debate is: are the processes active in the study of a foreign language essentially the same as the processes by which children acquire their mother tongue, or are they essentially different? Adherents of the natural approach to language learning, which originated in the second half of the 19th century, assume that the first is true. A naïve version of this view can often be found in descriptions of language learning methods, such as in the following text promoting the teach-yourself aids of the Assimil brand:

How did you learn to speak? You probably don't even know. You listened to your parents, gradually understanding the meanings of sounds, words, and then whole sentences. Then, once you had absorbed - or assimilated - the meanings of the word associations, you began to link words and form your own sen- 
tences. Assimil applied this same natural process adapting it to the abilities of adults, young and old. (http:// en.assimil.com/la-methode-assimil $)^{1}$

The extreme opposite view, in terms of both content and sophistication, can be found in the work of theoretical linguists from the generative camp, who argue for a fundamental difference. In their view, first language acquisition is based on an innate Universal Grammar, using mechanisms that for neurobiological reasons are available only to young children (see especially Meisel 2011 for a decided stance but with a balanced discussion). Scholars of second language acquisition research have often expressed views in between these opposite extremes, proposing that some processes and strategies are the same in first and second language acquisition while others differ (see Cook 2010 for an overview and a detailed discussion).

In this paper I will argue for a differentiated approach to the problem that acknowledges its Matryoshka-like nature: like the famous Russian dolls, each (seemingly simple) question entails another (seemingly simple) question, each seemingly unquestionable truth leads to new questions. This will become evident in Section 2, where I discuss three widely held views about fundamental characteristics of first language acquisition, and consider some of the questions they entail with respect to second language acquisition. In Section 3 I will turn to the similarities and differences that can be observed in the process of first and second language learning. My aim is to challenge the assumption that the differences between FLA and $\mathrm{SLA}^{2}$ are crucial for an understanding of how languages are acquired, and to call for a broader understanding of the "Language Making Capacity", as it is sometimes called. My interest in this topic grew, on the one hand, out of my own experience as a language learner and teacher, and on the other hand through teaching classes on language acquisition and learning.

\section{Fundamentals of language acquisition - crucial differences between FLA and SLA?}

\subsection{Ubiquity and necessity}

I will start with a statement that seems to be impossible to challenge:

(1) First language acquisition is a normal and necessary part of a human individual's development.

All children acquire a first language when exposed to it. Exceptions to this rule are only found in certain cases of severe disabilities that deprive the child not only of language, but also of many other aspects of physical and cognitive development. The normality of first language acquisition has never been doubted and does not have to be proved. It is possible to question the second part of thesis (1) - that first language acquisition is necessary for human development. However, it is nearly impossible to prove or disprove this. In any situation

1 I would mention that, without sharing the underlying assumptions, I am convinced of the advantages of the method for certain purposes - I used it successfully in the early phase of learning Polish and developing the listening skills that I needed when starting to work in Poznań.

2 For convenience, I will use the abbreviations FLA for first language acquisition and SLA for second language acquisition throughout this paper. 
where a child is deprived of exposition to human language (be it spoken or signed), other aspects accompanying normal physical, cognitive, and social development are likewise lacking, and the exact role of language within this complex cannot be determined.

In contrast, the normality and necessity of acquiring more than one language has been much debated by linguists and laymen alike, and is still a matter of controversy. On the one hand, the use of several languages by the same individual is a widespread phenomenon. While there are without doubt communities whose members rarely get in touch with other languages, on a worldwide scale multilingualism seems to be rather the rule than the exception in both industrialized and non-industrialized societies. Its normalness is often asserted in academic and popular articles, for example:

"multilingualism is humankind's norm" (Ellis 2005: 3);

"most of the world's population is bilingual or multilingual" (Valdés, online);

"there are many more bilingual or multilingual individuals in the world than there are monolingual" (Tucker 1999, cited in the Wikipedia entry on Multilingualism). ${ }^{3}$

Despite this fact, in linguistic studies monolingualism is often treated as if it were the norm. It is taken as the unmarked case, with bilingualism as the marked case. A telling example is given by Cruz-Ferreira: she reports that the American Association for the Advancement of Science invites scholars to discuss "how language is affected by bilingualism", but it would be strange to pose an analogous question about monolingualism (Cruz-Ferreira 2010: 2, citing AAASZ). ${ }^{4}$ However, if the use of more than one language is normal and natural for the greater part of humankind, then it is monolingualism and not multilingualism that is the marked case, and its causes and effects should be made the topic of research. This reasoning seems currently to be gaining ground in sociolinguistics, including studies in language planning and education policy. In 2008, the journal Sociolinguistic Studies devoted a special issue to monolingualism, probably the first of its kind.

In psycholinguistics, the idea of multilingualism as the unmarked case has not yet found much support. This is understandable, as it may have far-reaching consequences: it provokes disturbing questions about the normality and necessity of competence in more than one language for the fully-fledged development of an individual. The following quote from a renowned scholar of second language acquisition expresses a thought-provoking view about language acquisition and linguistic competence:

Going beyond this comes the argument that the overall theory of language acquisition has to accommodate the human potential for learning more than one language from the outset not as a footnote to the acquisition of the first language [...]. Looked at through the looking-glass of multi-competence, language acquisition is acquiring two or more languages; monolingual first language acquisition is a historical accident that stops the child reaching the normal human multi-competence state. The monolingual native speaker is languagedeprived; they would have acquired multi-competence in more than one language if their caretakers had not deprived them of a second language [...]. (Cook 2010: 156, emphasis mine)

3 While these claims seem plausible, they should be taken with caution, as they are based on estimates (with no or vague references to sources) or unconvincing arguments - for example, comparing the number of the world's languages (about 7000) with the number of states (about 200) does not say anything about the number of bilingual individuals in the world (it does not exclude the possibility that, say, only $10 \%$ of the world's population might use more than one language or that bilingualism occurs only in one corner of the world).

${ }^{4}$ The issue of the normality of multilingualism vs. monolingualism has been addressed in several academic articles. E. Ellis 2006 gives a critical overview of different views on monolingualism. See also Auer \& Wei 2007; Cruz-Ferreira 2010. 
Psycholinguistic and neurolinguistic research on bilingual children and adults has shown that there are differences in the processing of thoughts and language between monolingual and bilingual individuals (for overviews see Bialystok 2005; Nitsch 2007). The exact nature and the scale of these differences is still not clear, and maybe never will be. While earlier claims about general advantages of bilingualism (for example, that children raised bilingually are "more intelligent" than monolingual children) were not confirmed by more thorough research, there is good evidence for bilinguals' achieving better results in certain types of tasks that involve the processing and memorization of information. Bialystok explains the results of her experimental research with children by how acquiring and using more than one language shapes cognitive development:

The environmental experience of using two languages from childhood provides massive practice in the attention and inhibition centers of the prefrontal cortex and promotes their development. (Bialystok 2005: 428).

Studies with adults have shown that the regular use of more than one language has a positive effect on retaining executive control processes that generally decline in older individuals (Bialystok et al. 2004). In February 2011, another result of research on bilingualism and the brain became a headline event far beyond the scientific community: it was found that bilingualism delays the onset of dementia in a statistically significant way (see APS Media coverage).

If we adopt the point of view of bilingualism as the unmarked case, these results have to be formulated as "monolingualism advances the onset of dementia", "monolingualism speeds up age-related decline of cognitive abilities", and - to reformulate a statement about bilingualism made by Bialystok (2005: 428) - "monolingualism changes something fundamental about the way cognitive processes are shaped by young children".

At this point it is necessary to recall that the reverse of a false assumption does not automatically lead to a correct conclusion. The provocative statements formulated in the previous paragraph are useful if they lead to a reconsideration of assumed truths about monolingualism as the norm. However, conceiving monolingualism as an abnormity is clearly missing the point. Stimulation of brain activity and cognitive development has also been shown for other activities, for example, chess playing, but we do not think of non-chessplaying children as being hindered in their cognitive development. Instead, the conclusion that we should draw is that statement (1) may be broadened in one of the following ways:

(1') The acquisition of one or more languages is a normal and necessary part of a human individual's development.

(1') Language acquisition is a normal and necessary part of a human individual's development.

In my eyes, (1") expresses the main wisdom contained in (1), while avoiding the traps into which the word "first" may lure us. Some of the problems of the distinction between first and other languages will be discussed in the following section.

\subsection{Age}

Some of the essential properties of first language acquisition result from the fact expressed in the following statement:

(2) First language acquisition takes place in early childhood. 
At first sight, this statement seems to be uncontroversial - nobody doubts that infants and young children are engaged in acquiring their native language (or languages). However, there are two questions where doubt and disagreement are imaginable. The first one is whether first language acquisition, or more precisely, its beginning, is possible only during the first years of life - a question readily answered in the affirmative by most if not all linguists and psychologists. One should keep in mind that it is not possible to test this claim, and the empirical evidence from studies of so-called feral children is suggestive rather than conclusive. ${ }^{5}$ The construct of a Critical Period for the onset of first language acquisition thus remains a thesis that cannot be proved or disproved; it is of course a very plausible one. The second question is whether first language acquisition takes place during childhood only; in other words, at what age first language acquisition is completed (and whether it is ever complete at all). If one holds the opinion (as at least many non-linguists do) that school children, adolescents and even adults continue to perfect their native language, statement (2) becomes trivial and fragmentary. Young children certainly acquire the basics of a language, but who would claim that five-year-olds (or even ten-year-olds) have a perfect mastery of their mother tongue? Indeed, some linguists do seem to make such claims; see for instance the following statement from a popular textbook of linguistics:

From first words to virtual adult competence takes three to four years. (Fromkin et al. 2010: 351-352)

What is meant by "virtual adult competence", given that no five-year-old speaks like an adult?

The answer to the question of how long language acquisition goes on depends on which of the many aspects that make a language one has in mind. No-one doubts that new words are acquired at any age. Many linguists investigating child language have focused on certain aspects of grammar that are usually acquired before the age of five. The choice of these aspects is determined by theoretical considerations about the nature and structure of human languages and by a certain research interest. This is most evident in research based on the generative ("Chomskyan") approach to language, which is also the one underlying the textbook quoted above. Chomsky's theory of a Universal Grammar has inspired many investigations of first language acquisition where the primary interest is not to investigate how children acquire language in all its complexity, but rather to find evidence for certain postulates of the theory. One may argue that "language in all its complexity" is too broad and heterogeneous a subject, and for the scientific study of language acquisition it is necessary to select certain features (cf. Meisel 2011). But even for such features, "complete acquisition" may be attained much later (or never). Recent research by Ewa Dąbrowska and associates (see Dąbrowska 2008; 2012a; 2012b; and work cited there) has provided evidence that even some basic grammatical features, such as case marking in Polish or the passive in English, are not completely acquired in childhood. Instead, their acquisition continues, and adult native speakers may show different degrees of competence regarding these features. These findings challenge the conviction that "one will never find native speakers who acquired incomplete grammatical knowledge of their language" (Meisel 2011: 13).

Cf. DeKeyser \& Larson-Hall (2005: 89): "even in these cases, it was impossible to determine to what extent extreme social deprivation, maybe even food deprivation or sensory deprivation, may have been confounded with language input deprivation." 
A more accurate formulation of statement (2) thus may be the following:

(2') First language acquisition begins in infancy (at birth, or even before).

Turning now to second language acquisition, the questions provoked by statement (2') include: Can second language acquisition start at any age? If not, what limits the earliest possible beginning? Answers to these questions will depend on the distinction between first and second languages, which in turn is connected with assumptions about the nature of their acquisition. A second language may be defined as a language acquired after the first language - in this case, second language acquisition cannot start at birth, but only after (some substantial part of) a first language has been acquired. This view connects the question of the earliest possible beginning of second language acquisition with the question of the age at which first language acquisition is completed, which, as we have seen, can be answered in different ways. Alternatively, we may define a second language as a language acquired in addition to the first language.

In situations where a young child acquires two languages simultaneously, the question arises whether both are to be called first languages, or else how to determine which is the first and which is the second language. Often this question is answered with reference to age, with cut-off points varying between one month and five years. De Houwer (1995: 223) defines bilingual first language acquisition (resulting in two first languages) as "the acquisition of two or more languages from birth or from a month after birth". According to this definition languages whose acquisition starts later than in the first month of life are second languages. For McLaughlin (1978) the dividing point is much later: he calls first languages (the result of simultaneous as opposed to successive bilingualism) those acquired before the age of three. Meisel (2011: 204-206) argues for a dividing line between the age of three and four, combining evidence from child language research (from a UG perspective) and neurobiology.

In my own view, a more important factor than the age at which a child is first exposed to a language is the intensity and the kind of the exposure. To acquire a language as a first language, a substantial amount of input is needed, and exposure to the language has to be regular and continued. A second language may be familiar to a child from the very beginning of life (for example, heard from nurses in the hospital where they are born) but still felt to be second in order if it is not the main language used in the immediate environment. While many children in the world grow up bilingual, only some of them have more or less equal input in two languages in the first years of life. Even in bilingual families, often one language is dominant. Furthermore, it is normal that the input changes over time as the circumstances of life change - a crucial change is often noted when a child growing in a bilingual family starts attending a monolingual kindergarten. As stated above, bilingualism is the worldwide norm, but totally balanced bilingualism, or "equilingualism", as it is called by Baetens Beadsmore (1986: 9), is a rare exception; it may even be a fiction invented at the early stages of research on bilingualism. The idea of equilingualism is further connected with the view that every "normal" individual has perfect competence in their native language, where perfect competence is defined as that of a monolingual speaker.

Disentangling the distinction between first and second languages from the age factor, we may distinguish between two different research questions: (a) are first and second languages acquired in a different way?; and (b) are languages acquired differently in childhood (and 
up to which age)? Given the problem of determining what are first and second languages for young children, the second question seems to be more feasible for empirical research. Research on language acquisition at various ages and in various settings has shown that age effects can be observed at many different points in time, from early childhood to old age. ${ }^{6}$ These research results contest the the earlier view that there is one critical period for language acquisition. While the classic version of this thesis (starting with Lenneberg 1967) maintained that successful language acquisition is possible only when it starts before a certain age (mostly considered to be during puberty), current controversies center on the question whether and to what extent different mechanisms are active in language acquisition. I will turn to this controversy in the next section.

Another pair of questions connected to age and the distinction between first and second languages concerns the result of language acquisition: (a) does first language acquisition lead to different results - a different kind of competence - than second language acquisition?; and (b) is the result of language acquisition during childhood different from that of acquisition at later periods in life? Most non-linguists and many linguists have a ready answer to (b), namely that languages are best acquired during childhood and that someone starting to learn a second language after childhood (or after adolescence) will never reach the highest level of competence. However, this naïve view of the superiority of early vs. late language acquisition has to be qualified in several ways. First, it is not an absolute truth there are, after all, second language users who started acquisition as adults and have reached so-called native-like competence (Birdsong 2005 gives an estimate of 5\% of such L2 users). Second, even as a tendency it is not equally true for different components of competence phonological competence and native-like pronunciation being the most age-sensitive parts. For other components, circumstances of acquisition, domains and frequency of language use etc. may be more important factors than age; for example, the use of a language in education, or in one's professional life, or whether it is used in reading and writing or only in spoken form. These factors also play an important role for variant (a) of the question considered in this paragraph: there is in principle no difference in competence (at least in a nonChomskyan understanding) between first and second languages (as defined by order of acquisition, disregarding the age of onset). While for some time it was assumed that first and second languages were stored and processed in different parts of the brain, recent research has shown that this is not the case, or at least not necessarily (Perani \& Abutalebi 2005).

The first language a child acquires - the native language - may over time become weaker, and a second language may become dominant in some or all domains. As Cook (1999) argues, it is impossible to define the concept of native language by criteria other than that it is the first language (or a first language) acquired in childhood in the family. None of the characteristics often attributed to native languages or the native speaker (such as subconscious knowledge of rules, creativity of language use, or identification with a language community) is necessary or sufficient for a definition; all are also possible characteristics of a successfully acquired second language.

6 See Birdsong (2005) for a research overview, from which he draws the conclusion: "there is no apparent period within which age effects are observed; rather, they persist indefinitely" (Birdsong 2005: 109). Meisel (2007; 2011) attributes age effects during childhood to different sensible phases for parts of UG. Snedeker et al. (to appear) found that young children acquiring the language of their adopted family used different strategies depending on whether the age of adoption was 2-3 or 4-5 years. 
Furthermore, the results of early as well as late, first as well as second language acquisition are not irreversible - language competence once acquired may also be lost again. Interestingly, an early age of acquisition does not guarantee preservation; rather the opposite is true: it is more likely that after 10 years without contact a language acquired and used only from birth to age 5 will be completely lost, than with a language acquired and used only from, say, age 20 to $25 .^{7}$ Pallier et al. (2003) show in their study of Korean children adopted into French families that a first language replaced by a second language can be lost without leaving a trace in the brain, even if the replacement set in as late as age 8. While total attrition may be an extreme case, partial attrition is probably quite widespread, given that the use of different languages in different domains is normal, and it is common for a language acquired after the age of five to be used in important domains of an adult's life. Adolescents who are educated in a second language do not develop their first language to the same degree as those who receive education in their first language. Adults who conduct most of their daily life in a second language tend to lose a part of their native-language competence.

I conclude that language acquisition as well as language attrition may take place at any time during a person's life:

(2") Language acquisition is a lifelong experience.

This is not to deny that childhood is an especially important period for language acquisition. However, treating it as the only one, or the only one that is relevant for linguistic research, is too narrow a view and leads to the exclusion of many important aspects of human language. Similarly, the assumption that linguistic knowledge acquired in childhood is intrinsically superior to linguistic knowledge acquired later in life leads to a research perspective that ignores many facts of multilingual life, which is, as discussed above, the norm for most people of the world. This has been pointed out by Cook:

To call what the vast majority of L2 users achieve 'failure' is to accept that the only valid view of the world is that of the monolingual: knowing only one language is normal, knowing two is unusual. Only in a monolingual universe is a multi-competent person a failure for not speaking like a monolingual. (Cook 2010: 154)

\subsection{Acquisition vs. learning}

Second language acquisition is a phenomenon probably as old as the existence of different languages, but it became a subject of scientific research surprisingly late. For centuries, linguists and teachers had conceived knowledge of a second language only as the outcome of studying that language, the result of instructed learning. Only after research on first language acquisition had started to boom in the 1960s did the perspective - and the terminology - change from second language learning to second language acquisition. But was this switch appropriate? Controversy soon arose centering on the opposition of acquiring versus learning a language. As might be expected, the central terms of the controversy are often only vaguely defined. Generally speaking, "acquisition" is conceived as an unconscious process of building up linguistic knowledge through processing input without formal instruction, while "learning" is a conscious process, the activity of studying a language with the help of explanations given by a teacher and/or a book. A radical form of the Critical Period Hypoth-

7 I do not have a proof of this statement. Total attrition of a childhood language has been reported in several studies, but I am not aware of studies of total attrition of a later learned second language. 
esis mentioned above includes the postulate that language acquisition in this sense is possible only up to a certain age (for example, before puberty); afterwards there is only language learning, the results of which will never equal those of acquisition. Another approach that was much discussed in SLA research in the 1980s and 1990s was put forward by Stephen Krashen (1981), who proposed a model in which both acquisition and learning are integral parts. Acquisition is the more important process as it leads to primary linguistic knowledge, while learning results in metalinguistic knowledge used by a so-called monitor that controls and alters linguistic performance. In his view, learning can never turn into acquisition. This Monitor Model is still part of the curriculum of most courses on second language acquisition or applied linguistics, although few people would support it today.

Whether adults are able to acquire or only to learn a second language, or whether the linguistic knowledge that results from acquisition is principally different from the linguistic knowledge that results from learning, are questions that cannot be solved by empirical research. They depend on the theoretical approach chosen, and are of importance only relative to a certain theory. Therefore, most linguists interested in SLA have lost interest in establishing a difference in principle between acquisition and learning of second languages, and often use the two terms synonymously. A new discussion that has partly replaced the old controversy concerns different types of learning (see below).

When it comes to first language acquisition, a similar discussion centers around the question of whether and in what respects children "learn" their mother tongue, whether they are, or can be, "taught" to speak. A widespread opinion about this question, often to be found in linguistic textbooks, is expressed in the following statement:

(3) Children acquire their mother tongue without instruction.

Again, this thesis is most vehemently acclaimed within the generative school, among others by Noam Chomsky himself, who has always emphasized that language is essentially an innate capacity, not a learned skill. In an educational film Chomsky compares speaking to walking and declares categorically:

That we are taught to walk is impossible. And pretty much the same is true of language. Nobody is taught language. (Noam Chomsky in the film The Human Language Series, Part 2, 1994, cited after Fromkin et al. 2010: 330)

Whether we would subscribe to this statement will depend on our understanding of teaching and learning (and, of course, language). Obviously, children are not taught the basic grammar of their mother tongue by explicit descriptive rules ("if the subject is in the singular, the verb takes the ending $-s$ in the present tense"), but this is surely not the only way of teaching. If we include repeating, enforcing, correcting, presenting a model, or modifying input as teaching techniques, many people would surely hesitate to deny them any relevance for first language acquisition. There is anecdotal evidence of children resisting correction that is often cited in textbooks, but of course this cannot be taken as proof that the techniques mentioned never have any effect. ${ }^{8}$ The strong position taken by Chomsky and his followers of the impossibility of teaching language relies on a belief, not empirical evidence. Rather than adopting it as a dogma, it could be made the basis of research questions that may

8 I presume that anyone who has taught a foreign language to adults for some time can tell similar anecdotes about the "learning resistance" of some students, so there is no difference here in principle between children's FLA and adults' SLA. 
lead to new insights, such as: Which aspects of first language knowledge CAN be taught? How are these aspects taught? At what age is such teaching successful? If one accepts, as I have argued above, that first language acquisition is not completed in early childhood, the idea of teaching parts of a first language no longer seems so absurd. I have already cited Dąbrowska's pioneering research on the continuing acquisition of some aspects of grammar, such as the Polish genitive or the English passive. It includes an empirical study of the effects of explicit teaching: adult native speakers who had displayed non-complete acquisition of a feature performed significantly better in the tests after a short training session; the effects were long-lasting (Dąbrowska 2012a). Further investigations of this kind may show to what extent a "focus on form" (to use a popular label of SLA research and practice) is a beneficial if not a necessary part of first language acquisition.

The strict opposition of acquisition and learning can also be challenged if they are not conceived as homogenous: there may be different ways of both learning and acquiring, or simply different ways of acquiring a language, of which some resemble our prototypical conception of "learning" more than others. In SLA research and applied linguistics, a distinction is often made between explicit and implicit learning (DeKeyser 2003). ${ }^{9}$ The concept of implicit learning is similar to that of "acquisition" as defined at the beginning of this section: it refers to the building of knowledge by processing data, also to the acquisition of some aspects (for example, of grammar) present in the input while focusing on other aspects (for example, the content or goal of a communicative event). Explicit learning, on the other hand, refers to learning the aspect that is in focus.

DeKeyser \& Larson-Hall argue that there are crucial differences regarding preference for and the effectiveness of one of these ways of learning with respect to age: "Children can learn very little explicitly; adults can learn very little implicitly" (DeKeyser \& LarsonHall 2005: 101). In their opinion, this difference is at the heart of age effects in language acquisition and justifies the postulation of a Critical Period, as "language acquisition from mere exposure (i.e., implicit learning), the only mechanism available to the young child, is severely limited in older adolescents and adults" (89). These statements are based on empirical research, and there is little doubt that they are correct as general tendencies. One may add that, while all children seem to be good at implicit learning, in older learners there are considerable individual differences: some adults profit more from implicit learning, some rely almost exclusively on explicit learning, while still others combine both types of learning (these are often the most successful students in language classes using a communicative approach).

In the USA and several other Western countries, first language acquisition research in the second half of the 20th century was dominated by the generativist approach to language. Acquisition of grammar was therefore most often explained as the unfolding of innate linguistic rules, adjusting universal principles to the specific rules of the language of the child's environment. Towards the end of the 20th century, alternative approaches and models were gaining ground, especially constructivism. Interestingly, the presence of alternative models of explanation has not only led researchers to abandon or to modify their previous theory (as is usually the case), but also to consider the possibility of different mechanisms of acquisi-

9 A partially overlapping distinction is made between intentional and incidental learning, which I will not consider here (see Hulstijn 2003). 
tion "coexisting". One possibility of such coexistence is the division of labor according to the aspect of grammar that is acquired. Generativists still claim that it is the very core that is acquired by parameter-setting, while anything acquired by other mechanisms is at the periphery. Dąbrowska (2000), among others, has challenged this view by arguing that essential parts of the Polish case system cannot be acquired by parameter-setting. As part of her conclusions she states:

First, the "periphery" is not as peripheral as some would have us believe: in fact, the "core" constitutes only a very small part of linguistic knowledge. At the end of the day, the elaborate clanking machinery of PP theory does not accomplish very much, and most of what the child needs to know in order to communicate successfully must be acquired with the help of learning mechanisms other than parameter-setting. Secondly, given that some aspects of language must be learned, we must seriously consider what mental capacities are necessary to learn them. (Dąbrowska 2000: 93)

Note that Dąbrowska uses the word "learning" here for (parts of) first language acquisition.

In their study on child second language acquisition under circumstances that resemble first language acquisition - children from China and Eastern Europe adopted into Englishspeaking families between the age of two and five - Snedeker et al. (to appear) observed different mechanisms used by younger and older subjects. It is also possible that different mechanisms are involved in the acquisition of any particular feature at different stages. For example, the first phase(s) of acquisition may be triggered by innate mechanisms, but its continuation may depend more on the kind of input and the experience an individual has with different varieties and modes of language.

In any case it seems plausible to assume that in a process as complex as acquiring language, different mechanisms are at work and interact. Isolating a small set of supposedly innate mechanisms and opposing them to everything else is likely to hinder a full understanding of language acquisition, especially if research focuses only on that small set and neglects other aspects for ideological reasons. A binary opposition of acquisition vs. learning, or implicit vs. explicit learning is probably too simple, and finer-grained differentiations will be more fruitful.

\section{Observing differences and similarities}

It is often said that all children acquire their mother tongue in the same way and at the same age. Second language acquisition, on the other hand, is characterized by a variety of individual differences. It is worth scrutinizing this assumed opposition by exploring questions such as the following: How uniform is first language acquisition - are there not individual differences here too? Which aspects that make up the uniformity of first language acquisition are found in second language acquisition as well? And, maybe most interesting for SLA research, but up to now least explored: Can individual preferences in second language acquisition be linked to characteristics of first language acquisition by the same speaker? Are there ways to language that some individuals prefer in general? Do such preferences change with age, or with growing experience with more than one language?

Individual differences in first language acquisition have been found in rate and in "style" (see Bates et al. 1995 for an overview). The first aspect is easier to observe and to measure. Evidently, not all children start to speak at exactly the same age. While textbooks teach that the 
first word is usually uttered around the first birthday, cross-sectional studies have confirmed that a considerable range is normal: early talkers may start with 8 months, late talkers towards the end of their second year. At the age of 16 months a vocabulary range of 0-155 items was found in children from American English families (Bates et al. 1995). A longitudinal study of 128 children carried out in the 1970s in the UK (the Bristol Project, see Wells 1985) showed that the order in which English children acquired certain aspects of grammar, semantics and pragmatics was relatively fixed, while there was considerable difference concerning the rate of progress. Skehan (1987: 3) comments on these findings: "the implication of this variability in rate is that the child brings a great deal of autonomy to the task of language learning." When the children who took part in the Bristol Project were in their teenage years, a smaller study was conducted that investigated their success in second language learning in school. Skehan (1987) found a correlation between the speed of first language acquisition and the achievements in second language classes. Research on the acquisition of first and second languages by the same individuals over a time of more than 10 years are very rare, and the results of Skehan's study give rise to several questions that cannot be answered at present. A teenager's success in school may depend on many factors that are not directly related to language aptitude. The correlation Skehan found between the amount of native language input in the pre-school years and the ease of second language learning in secondary school may indicate the benefits of a certain style of child-raising: parents who talk more to their children will also be more concerned with their education, and for example stimulate reading and other language-related activities, or provide exposure to different styles and genres.

Apart from differences in rate, some (mostly longitudinal) studies of child language have revealed differences in the way children approach the task of language acquisition. Individual differences in "style" have been found concerning various aspects of language: phonology, vocabulary, grammar and pragmatics (Bates et al. 1995: 120-133). For example, "segmentally oriented" children clearly pronounce individual sounds, while "prosodically oriented" children pay more attention to stress, number of syllables, and intonation. Some children make early use of personal pronouns, while others prefer the use of nouns and names when talking about persons, including themselves. Concerning the acquisition of morphology, the amount of overgeneralizations (such as goed, bringed) may vary greatly. Another difference concerns what children talk about in their early stages and what kind of speech acts they produce more often: some children talk more about objects, others more about persons; some children early on make various speech acts such as questions or demands, while in the speech of others we find predominantly statements. Some researchers have suggested that several such differences correlate - that there are two different styles in language acquisition, or roughly two types of young acquirers. However, there is not enough evidence for this thesis, and I rather suspect that a division of children into two basic types is too simplistic. It would be very interesting to investigate whether an individual shows preferences such as the ones mentioned here in both first and second language acquisition, or, more accurately, in early as well as later language acquisition. For a feature such as orientation towards prosody such a thesis seems fairly plausible ${ }^{10}$, though not necessarily true. I am not aware of any empirical research on these aspects.

${ }^{10}$ From my personal experience with second language learning and anecdotes my parents used to tell about my early utterances as a child, I suspect that I have always been "prosodically oriented". 
Having challenged the uniformity of first language acquisition, I now turn to aspects that are undoubtedly at least very similar in children's acquisition of language, but have no exact parallels in later second language acquisition. An obvious point is the early stages of FLA that are connected to physiological and cognitive maturation - an adult will never again go through a stage of babbling before uttering their first words. This may have significant consequences for the acquisition of phonology. Small children have already acquired a substantial part of their native language's phonology before they start combining words, while adults learning a second language sometimes acquire a considerable vocabulary and are able to form elaborate sentences in a second language without fully mastering phonological distinctions.

Some researchers have proposed stages of SLA that resemble those of FLA, namely a (non-obligatory) silent period at the onset, a stage of formulaic speech characterized by utterances of single words and expressions learnt as wholes, followed by a stage marked by structural and semantic simplification, gradual acquisition of grammatical morphemes and finally elaborate sentence structures (Trawiński 2005: 54). However, it is doubtful how far this sequence is typical for SLA in various situations. For example, complex sentences may occur long before case morphology has been mastered.

Still, some similarities may indeed be found between the language at an early stage of adult SLA and the speech of a young child, and it is worth considering these similarities. The following is an illustration of the active vocabulary of a French student after six weeks in Poland (she did not study the language systematically). This sample was not drawn up on purpose or in any systematic way - the student simply wrote down all the Polish that came to her mind because she was unable to fulfill another task that her colleagues were doing at the time. (The name has been changed.)

\begin{tabular}{lll}
\hline Nie rozuviem & Tak & miwo mi \\
nie viem & nie & marchew \\
pzepracham & prosze & kantor \\
djękuye & Ratta & bankomat \\
djindobre & jeden & pirogi \\
nie mowie po polsku & mam na imię Marie & pomidor \\
jestem francsi & pan & serem \\
dowidzenia & pani & woda \\
smatch nego & matka & piwa \\
nazdrowia & papa & sok \\
Kto to jest? & Tchecht & \\
Stary brovar & na razie & \\
\hline
\end{tabular}

This sample reflects a "formulaic stage" - utterances that consist of more than one word (versions of Standard Polish nie rozumiem 'I don't understand', nie mówię po polsku 'I don't speak Polish', Kto to jest? 'who is it?', etc.) were certainly learnt as wholes and not composed by the speaker. Likewise the inflected form serem (literally 'with cheese') has most probably entered the vocabulary unanalyzed. There are two categories of words in this list: nouns (designating concrete objects and places) and pragmatic words and phrases ('hello', 'goodby', 'see you', 'cheers', 'thank you', etc.). The same two categories prevail in the early vocabulary of children. The preference for nouns over verbs or adjectives at the beginning of language development has been the subject of various research (see Li \& Fang 2011 for 
a corpus analysis of the CHILDES database of English child language; Gentner \& Boroditsky 2009 for a comparative study of typologically diverse languages and for a concise summary of previous research). It has been proposed that the preference for concrete nouns in the early vocabulary of children acquiring various languages reflects their cognitive development: concrete nouns are easier to handle than abstract concepts or verbs. Of course, cognitive development cannot be the reason why adults build up their early L2 vocabulary with the same kind of words when they are capable of handling abstract and complex concepts in their first language. One of the possible reasons is that in many languages verbs are more tightly embedded into the grammatical structure of a language and therefore harder to isolate and translate without a grammatical context. Nouns and pragmatic words like greetings are also usually the first lexical items that get borrowed from one language into another. The parallels in early vocabularies in FLA and SLA (in cases where acquisition is not strongly guided by instruction) are striking. They may of course be superficial, the accidental result of entirely different mechanisms, but they may also at least partly have a common ground.

Research into child language in the 1960s and 1970s revealed that the order in which grammatical meanings and expressions are acquired is fairly similar across children. Several researchers have tried to show a similar "natural order" in second language acquisition; however, the results are not very convincing. It seems that the order of acquisition of grammar in SLA depends on a variety of factors and is on the whole much less predictable than the order of acquisition in FLA. A more general aspect of the acquisition of grammar, however, can be observed in both FLA and SLA: grammatical development follows lexical development (for FLA see Bates \& Goodman 2001). Maybe this is no absolute rule in SLA: some adults may learn and effectively use grammatical rules in a second language while possessing a relatively small active vocabulary. However, these learners are very rare (usually learners with an extraordinary aptitude for grammar are also good at acquiring words). For the great majority of second language users, a growing vocabulary is a prerequisite for a growing mastery of the grammar, and explicit teaching of grammar may have little effect if the students' lexicon is too small to anchor the grammatical regularity in question.

A still more general observed similarity between first and second language acquisition is that comprehension is ahead of production: children always understand more words and more difficult constructions than they are able to produce, and the same is true of second language learners. This fact may seem trivial, but in my view it is an important aspect of language development and may be worth more detailed research.

\section{Conclusions}

In this paper I have tried to challenge the view that there is an essential difference between first and second language acquisition. I do not deny that there are some fundamental differences, but argue for another interpretation of these differences. One of my points is not to confuse the opposition first vs. second language with the opposition child vs. adult. For example, the first part of the following statement is undeniably true:

$[\ldots]$ infants who are learning language are also engaged in learning about how the world works. In comparison, L2 learners already know a great deal about the world. (MacWhinney 2005: 49) 
The accuracy of the second part, on the other hand, depends partly on the definition of second language, as discussed in Section 2.2, but in any case we would have to exclude child second language acquisition. Even a five-year-old is still learning a great deal about the world. There are obvious reasons why child language development should differ from language development at a later point in life. If considered in isolation from the age factor, the only reason why the acquisition of a second language should differ in principle from the acquisition of the first language is that it is SECOND - which means that the person acquiring it already knows (substantial parts of) another language, and therefore also knows essential aspects of language in general.

Knowing a language, and knowing about language in general, entails so much more than the specific aspects of grammar that have been the focus of FLA research for several decades. In the past, especially in the 1960s and 1970s, ideas and paradigms were transferred - not very fruitfully - from FLA research to SLA research: for example, the idea of a "Language Acquisition Device" or an innate Universal Grammar, the Critical Period, a fixed Morpheme Acquisition Order, and others. After a period in which the two fields developed more independently, it may now be time to consider what first language acquisition research may learn from research on the acquisition, development, and use of other languages.

\section{References}

AAASZ $=$ Homepage of the American Association of the Advancement of Science, Section Z Linguistics and Language Studies at: http://spot.colorado.edu/ menn/AAASZ. (Accessed 2013-05-27)

APS Media coverage = Association of Psychological Science, Media Coverage of "Bilingual Minds". http://www. psychologicalscience.org/index.php/publications/journals/pspi/pspi-archive/media-coverage-bilingual. (Accessed 2013-05-18)

Auer, Peter \& Li Wei. 2007. Introduction: Multilingualism as a problem? Monolingualism as a problem? In Auer, Peter \& Wei, Li (eds.), Handbook of multilingualism and multilingual communication, 1-13. Berlin, New York: Mouton de Gruyter.

Bates, Elizabeth \& Goodman, Judith C. 2001. On the inseparability of grammar and the lexicon: evidence from acquisition. In Tomasello, Michael \& Bates, Elizabeth (eds.), Language development: essential readings, 134-162. Malden, Mass.: Blackwell.

Bates, Elizabeth \& Dale, Philip S. \& Thal, Donna. 1995. Individual differences and their implications for theories of language development. In Fletcher, Paul (ed.), The handbook of child language, 96-151. Oxford: Blackwell.

Baetens Beardsmore, Hugo. 1986. Bilingualism: Basic principles. Second edition. Clevedon: Multilingual Matters.

Bialystok, Ellen. 2005. Consequences of bilingualism for cognitive development. In Kroll, Judith F. \& de Groot, Annette M. B. (eds.), Handbook of bilingualism. Psycholinguistic approaches, 417-432. Oxford: Oxford University Press.

Bialystok, Ellen \& Craik, Fergus I. M. \& Klein, Raymond \& Viswanathan, Mythili. 2004. Bilingualism, aging, and cognitive control: evidence from the Simon task. Psychology and Aging 19(2). 290-303.

Birdsong, David. 2005. Interpreting age effects in scond language acquisition. In Kroll, Judith F. \& de Groot, Annette M. B. (eds.), Handbook of bilingualism. Psycholinguistic approaches, 109-127. Oxford: Oxford University Press.

Cook, Vivian. 1999. Going beyond the native speaker in language teaching. TESOL Quarterly 33(2). 185-209.

Cook, Vivian. 2010. The relationship between first and second language learning revisited. In Macaro, E. (ed.), The continuum companion to second language acquisition, 137-157. London: Continuum.

Cruz-Ferreira, Madalena. 2010. Multilingualism, language norms and multilingual contexts. In Cruz-Ferreira, Madalena (ed.), Multilingual norms, 1-17. Frankfurt/Main: Lang. 
Dąbrowska, Ewa. 2000. Could a Chomskyan child learn Polish? The logical argument for learnability. In Perkins, Michael \& Howard, Sara (eds.), New directions in language development and disorder, 85-96. New York: Plenum.

Dąbrowska, Ewa. 2008. The later development of an early-emerging system: The curious case of the Polish genitive. Linguistics 46(3). 629-650.

Dąbrowska, Ewa. 2012a. Different speakers, different grammars. Individual differences in native language attainment. Linguistic Approaches to Bilingualism 2. 219-253.

Dąbrowska, Ewa. 2012b. Ultimate attainment in first and second language acquisition. In Proceedings of the JACET 51st International Convention, JACET. http://www.northumbria.ac.uk/sd/academic/sass/about/humanities/linguistics/linguisticsstaff/e_dabrowska/e_dabrowskafullpub. (Accessed 2013-06-06)

DeKeyser, Robert. 2003. Implicit and explicit learning. In Doughty, Catherine \& Long, Michael H. (eds.), The handbook of second language acquisition, 319-348. Malden: Blackwell.

DeKeyser, Robert \& Larson-Hall, Jenifer. 2005. What does the critical period really mean? In Kroll, Judith F. $\&$ de Groot, Annette M. B. (eds.), Handbook of bilingualism. Psycholinguistic approaches, 88-108. Oxford: Oxford University Press.

Ellis, Elizabeth. 2006. Monolingualism: The unmarked case. Estudios die Sociolingüistica 7(2). 173-196.

Ellis, Nick. 2005. Introduction to part I: Acquisition. In Kroll, Judith F. \& de Groot, Annette M. B. (eds.), Handbook of bilingualism. Psycholinguistic approaches, 3-8. Oxford: Oxford University Press.

Gentner, Dedre \& Boroditsky, Lera. 2009. Early acquisition of nouns and verbs: evidence from Navajo. In Gathercole, Virginia, (ed.), Routes to language: Studies in honor of Melissa Bowerman, 5-36. New York: Taylor \& Francis.

de Houwer, Annick. 1995. Bilingual language acquisition. In Fletcher, Paul (ed.), The handbook of child language, 219-250. Oxford: Blackwell.

Hulstijn, Jan H. 2003. Incidental and intentional learning. In Doughty, Catherine \& Long, Michael H. (eds.), The handbook of second language acquisition, 349-381. Malden: Blackwell.

Krashen, Stephen. 1981. Second language learning and second language acquisition. Oxford: Pergamon Press.

Lenneberg, Eric. 1967. Biological foundations of language. New York: Wiley.

Li, Hanhong \& Fang, Alex C. 2011. Word frequency of the CHILDES corpus: Another perspective of child language features. ICAME Journal 35. 95-116.

MacWhinney, Brian. 2005. A unified model of language acquisition. In Kroll, Judith F. \& de Groot, Annette M. B. (eds.), Handbook of bilingualism. Psycholinguistic approaches, 49-67. Oxford: Oxford University Press.

McLaughlin, Barry. 1978. Second-language acquisition in childhood. New York: Wiley.

Meisel, Jürgen. 2011. First and second language acquisition: parallels and differences. Cambridge: Cambridge University Press.

Nitsch, Cordula. 2007. Mehrsprachigkeit: Eine neurowissenschaftliche Perspektive. In Anstatt, Tanja (ed.), Mehrsprachigkeit bei Kindern und Erwachsenen, 47-68. Tübingen: Attempto Verlag.

Pallier, C. \& Dehaene, S. \& Poline, J.-B. \& LeBihan, D. \& Argenti A.-M. \& Dupoux, E. 2003. Brain imaging of language plasticity in adopted adults: Can a second language replace the first? Cerebral Cortex 13. 155-161.

Perani, Daniela \& Abutalebi, Jubin. 2005. The neural basis of first and second language processing. Current Opinion in Neurobiology 15(2). 202-206.

Skehan, Peter. 1987. Individual differences, input, and interaction: A comparison of first and foreign language learning. JALT Journal 9(1), 1-14.

Snedeker, Jesse \& Geren, Joy \& Shafto, Carissa L. To appear. Different paths: Changes in second-language acquisition between three and five years of age. Pre-print version available at: http://www.wjh.harvard.edu/ lds/ index.html?snedeker.html

Trawiński, Mariusz. 2005. An outline of second language acquisition theories. Kraków: Wydawnictwo Naukowe Akademii Pedagogicznej.

Tucker, G. Richard. 1999. A global perspective on bilingualism and bilingual education. Website of the Centre for Applied Linguistics at: http://www.cal.org/resources/Digest/digestglobal.html. (Accessed 2013-05-20].

Valdés, Guadalupe. Online. Multilingualism. Website of the Linguistic Society of America at: http://www.linguisticsociety.org/content/multilingualism. (Accessed 2013-05-20)

Wells, Gordon. 1985. Language development in pre-school years. Cambridge: Cambridge University Press. 